\author{
Ferdinando Maggioni \\ Filippo Dainese \\ Federico Mainardi \\ Carlo Lisotto \\ Giorgio Zanchin
}

\section{Cluster-like headache after surgical crystalline removal and intraocular lens implant: a case report}

Received: 13 January 2005

Accepted in revised form: 16 February 2005

Published online: 8 April 2005

F. Maggioni $(\bowtie) \cdot$ F. Dainese $・$ F. Mainardi

G. Zanchin

Headache Centre,

Department of Neurosciences,

University of Padua,

Padua, Italy

e-mail: ferdinando.maggioni@unipd.it

Tel.: +39-049-8213600

Fax: +39-049-8751770

C. Lisotto

Headache Centre,

Hospital S. Vito al Tagliamento,

Pordenone, Italy

\begin{abstract}
Cluster headache $(\mathrm{CH})$ is
a well characterized primary

headache disorder. Nevertheless, symptomatic $\mathrm{CH}$ has been reported in association with various underlying diseases. Symptomatic cluster headache related to ocular pathologies have been rarely described. We report a case consequent to a surgical operation for cataract.
\end{abstract}

Key words Cluster headache • Cataract • Intraocular lens implant • Symptomatic cluster headache

\section{Introduction}

Cluster headache $(\mathrm{CH})$ is a well characterised primary headache disorder. The diagnostic criteria, codified in 1988 [1] and reviewed in 2004, can be found in Chapter 3 of the International Headache Society (IHS) classification [2]. Nevertheless, symptomatic $\mathrm{CH}$, or cluster-like headache (CLH), has been reported with various underlying diseases [3,4]. Some, moreover, are caused by traumatic accidents or are related to surgery. In the majority of these cases the close temporal proximity between the onset of $\mathrm{CH}$ attacks and the traumatic or surgical events are beyond mere coincidence and, generally, present characteristics indicative for the chronic form of $\mathrm{CH}$ [5]. In a few of these symptomatic cases the clinical features fulfil IHS criteria for idiopathic $\mathrm{CH}$ and when this happens there are difficulties in the diagnosis. We report a case with the onset of $\mathrm{CH}$, following surgical removal of crystalline for cataract and implant of intraocular lens (IOL). The ophthalmologic secondary cluster-like cases are reviewed and the possible physiopathological mechanisms are discussed.

\section{Case history}

The patient was a 55-year-old man who smoked 5 cigarettes each day, did not drink alcohol, had no relevant 
medical history and was on no medication. There was no family history of headache. In January 2003, the patient had undergone a cataract surgery with IOL implantation in the left eye, with local anaesthesia and without complications. The patient was discharged some hours after the operation. The pathogenesis of the cataract was unclear because the patient had not presented with associated pathologies or a traumatic event. Routine laboratory studies: blood chemistry, urine analysis, ECG and chest X-ray performed before the operation were negative. Within three weeks of the surgery, the patient developed a daily, strictly left-side periorbital pain. The attacks were of severe intensity, reported as 10 on a scale from 1 to 10 , occurring, during the first two months, once in the early morning (about $3 \mathrm{am}$ ), and then twice, with another attack after lunch (about $2 \mathrm{pm}$ ). The attacks lasted 45-60 minutes and were accompanied by ipsilateral lacrimation and nasal congestion. Usually a mild ptosis was present without a certain miosis; during the attacks the patient was restless; between the attacks the patient was pain-free and the autonomic associated features disappeared. No nausea, vomiting, photo- or phonophobia were reported. He was treated in the first instance with NSAIDs, with poor efficacy.

The patient visited our headache centre 4 months after the surgery. Some days before this he went to an oculist, without alteration. Neurological and physical examinations were completely normal, in particular, no residual autonomic features were present; brain computed tomography (CT), angiographic $\mathrm{CT}$ of intracerebral vessel and a cerebral magnetic resonance (MRI) with gadolinium were normal. The attacks were completely responsive to the treatment with subcutaneous sumatriptan $6 \mathrm{mg}$. He started a treatment with prednisone $70 \mathrm{mg} /$ day for five days, gradually tapering off after three weeks, with disappearance of attacks. At the follow-up there was no recurrence (15 months).

\section{Discussion}

The case reports of cluster secondary to ophthalmologic pathologies are quite rare, and may be secondary to inflammation, traumatism or post-exenteration. We found seven cases in the literature after eye enucleations [6], two secondary to orbital myositis $[7,8]$ and one secondary to Herpes zoster ophthalmicus [9]. To the best of our knowledge, no cases of $\mathrm{CH}$ after surgery for cataract have been described. The pain usually presents post-operatively, occurring in approximately $8 \%$ of the patients, and is not specific and related to the zone of intervention $[10,11]$. In our patient the post-operative period was pain-free, but about 20 days after surgery he presented a specific symptomatology, fulfilling the IHS diagnostic criteria for $\mathrm{CH}$ [2]. In a great number of case reports, it is often difficult to point out if there is a real causal correlation between the organic lesion and $\mathrm{CH}$, or if it is just coincidence. The patient had a history of smoking, which would predispose him for the development of $\mathrm{CH}$ [12]. In our opinion, there are three points to consider regarding whether a true causal relation exists between the surgery and the development of $\mathrm{CH}$ in this case. First, the temporal relation with the operation is suggestive of a secondary form. Second, the onset of $\mathrm{CH}$, at the age of 55 years, is remarkably late in the life of the patient; the mean age of onset in primary episodic $\mathrm{CH}$ reported in the literature is 28 years and 36 for chronic $\mathrm{CH}$ [13]. Third, because the active phases of episodic cluster periods usually last from 1 to 2 months [13], the clinical presentation resembles a chronic form, even if not enough time elapsed to meet IHS criteria for chronic form; this form of presentation is common to secondary $\mathrm{CH}$, particularly post-trauma and postsurgery [3-5]. Whereas, in patients with idiopathic $\mathrm{CH}$, $82 \%$ have episodic, and only $10 \%$ begin with chronic form [14].

The exact physiopathology of $\mathrm{CH}$ is not known and a unifying explanation is not yet available. Proposed mechanisms include activation of the trigeminal neurovascular system. We can see that a great number of symptomatic cases are secondary to lesions localised in highly sensitive innervated portions of the head, in particular meninges, eyes, teeth and vessels [15]. In particular, for the cases involving the periorbital region, we hypothesise that the activation of the ophthalmic division of the trigeminal nerve would provoke pain in the periorbital region and reflex activation of parasympathetic fibres arising in the superior salivatory nucleus, leading to excessive gland secretion (lacrimation, nasal congestion and eye injection), and dilation of internal carotid artery. Sympathetic dysfunction (Horner's syndrome of miosis and ptosis) could be secondary to compression of fibres arising in the superior cervical ganglion over a dilated carotid wall [14]. Therefore, in this case the involvement of the first division of trigeminal nerve would activate the trigeminal pathway and probably the hypothalamic connection with the pain modulation system of the brainstem [16].

To the best of our knowledge, no cases of $\mathrm{CH}$ after surgery for cataract have been described. Cluster symptomatic reports are an important matter of study, which could bring useful "experimental" elements to knowledge of the $\mathrm{CH}$ pathogenesis. 


\section{References}

1. Headache Classification Committee of the International Headache Society (1988) Classification and diagnostic criteria for headache disorders, cranial neuralgias and facial pain. Cephalalgia 8[Suppl 7]:1-96

2. Headache Classification Subcommittee of the International Headache Society (2004) The International Classification of Headache Disorder, 2nd edn. Cephalalgia 24[Suppl 1]:1-160

3. Mainardi F, Dainese F, Maggioni F, Trucco M, Palestini C, Zanchin G (2003) Cluster like headache: an overview. Cephalalgia 23:679

4. Giraud P, Jouanneau E, Borson-Chazot L, Lanteri-Minet M, Chazot G (2002) Cluster-like headache: a literature overview. J Headache Pain 3:71-78

5. Soros P, Frese A, Husstedt IW, Evers S (2001) Cluster headache after dental extraction: implication for the pathogenesis of cluster headache?

Cephalalgia 21:619-622

6. Evers S, Soros P, Brilla R, Gerding H, Husstedt IW (1997) Cluster headache after orbital exenteration. Cephalalgia 17:680-682
7. Lee MS, Lessell S (2002) Orbital myositis posing as cluster headache. Arch Neurol 59:635-636

8. Rubin PA, Chen VN, Acquadro MA (1996) Cluster headache presenting with orbital inflammation. Ophthalmic Surg Lasers 27:143-146

9. Sacquegna T, D'Alessandro R, Cortelli P, de Carolis P, Baldrati A (1982) Cluster headache after herpes zoster ophthalmicus. Arch Neurol 39:384

10. Barker JP, Vafidis GC, Hall GM (1996) Postoperative morbidity following cataract surgery. A comparison of local and general anesthesia. Anesthesia 51:435-437

11. Koay P, Laing A, Adams K, Branney S, Mathison J, Freeland F, Studley M, Black H (1992) Ophthalmic pain following cataract surgery: a comparison between local and general anaesthesia. Br J Ophthalmol 76:225-227
12. Manzoni GC (1999) Cluster headache and lifestyle: remarks on a population of 374 male patients. Cephalalgia 19:88-94

13. Nappi G, Russel D (2000) Symptomatology of cluster headache. In: Olesen J, Tfelt-Hansen P, Welch K (eds) The headaches. Lippincott, Williams and Wilkins, Philadelphia, pp 717-724

14. Dodick DW, Rozen TD, Goadsby PJ, Silberstein SD (2000) Cluster headache. Cephalalgia 20:787-804

15. Rahmann A, Husstedt IW, Evers S (2003) Cluster headache after removal of a subarachnoid cyst: a case report. Headache 43:130-131

16. Malick A, Strassman AM, Burstein R (2000) Trigeminohypothalamic and reticulohypothalamic tract neurons in the upper cervical spinal cord and caudal medulla of the rat. J Neurophysiol 84:2078-2112 